\title{
HAVE NEWER CARDIOVASCULAR DRUGS REDUCED HOSPITALIZATION? EVIDENCE FROM LONGITUDINAL COUNTRY-LEVEL DATA ON 20 OECD COUNTRIES, 1995-2003
}

\author{
Frank R. Lichtenberg \\ Working Paper 14008 \\ http://www.nber.org/papers/w14008
NATIONAL BUREAU OF ECONOMIC RESEARCH
1050 Massachusetts Avenue
Cambridge, MA 02138

May 2008

I am extremely grateful to Peter Stephens and IMS Health for providing pharmaceutical data. The views expressed herein are those of the author(s) and do not necessarily reflect the views of the National Bureau of Economic Research.

NBER working papers are circulated for discussion and comment purposes. They have not been peerreviewed or been subject to the review by the NBER Board of Directors that accompanies official NBER publications.

(C) 2008 by Frank R. Lichtenberg. All rights reserved. Short sections of text, not to exceed two paragraphs, may be quoted without explicit permission provided that full credit, including $\odot$ notice, is given to the source. 
Have Newer Cardiovascular Drugs Reduced Hospitalization? Evidence From Longitudinal

Country-Level Data on 20 OECD Countries, 1995-2003

Frank R. Lichtenberg

NBER Working Paper No. 14008

May 2008

JEL No. I12,O33,O51,O52,O56

\begin{abstract}
This study examines the effect of changes in the vintage distribution of cardiovascular system drugs on hospitalization and mortality due to cardiovascular disease using longitudinal country-level data. The vintage of a drug is the first year in which it was marketed anywhere in the world. We use annual data on the utilization of over 1100 cardiovascular drugs (active ingredients) in 20 OECD countries during the period 1995-2003.

Countries with larger increases in the share of cardiovascular drug doses that contained post-1990 or post-1995 ingredients had smaller increases in the cardiovascular disease hospital discharge rate, controlling for the quantity of cardiovascular medications consumed per person, the use of other medical innovations (CT scanners \& MRI units), potential risk factors (average consumption of calories, tobacco, and alcohol), and demographic variables (population size \& age structure, income, and educational attainment). The estimates also indicate that use of newer cardiovascular drugs has reduced average length of stay and the age-adjusted cardiovascular mortality rate, but not the number of potential years of life lost due to cardiovascular disease before age 70 per 100,000 population.
\end{abstract}

The estimates indicate that if drug vintage had not increased during 1995-2004, hospitalization and mortality would have been higher in 2004 . We estimate that per capita expenditure on cardiovascular hospital stays would have been 70\% (\$89) higher in 2004 had drug vintage not increased during 1995-2004. Per capita expenditure on cardiovascular drugs would have been lower in 2004 had drug vintage not increased during 1995-2004. But our estimate of the increase in expenditure on cardiovascular hospital stays is about 3.7 times as large as our estimate of the reduction in per capita expenditure for cardiovascular drugs that would have occurred (\$24).

Frank R. Lichtenberg

Graduate School of Business

Columbia University

3022 Broadway, 614 Uris Hall

New York, NY 10027

and NBER

frank.lichtenberg@columbia.edu 
New drugs tend to be more expensive than old drugs. Many people might therefore expect greater use of new drugs to increase total medical expenditure. This is not necessarily the case, however. If new drugs are more effective than older drugs, use of newer drugs might reduce other medical (e.g. hospital) expenditure more than it increases drug expenditure.

A number of previous studies have investigated the hypothesis that use of newer drugs has reduced other medical expenditure. Some of these studies have investigated whether new drugs in general-i.e., drugs in all therapeutic classes and for all diseaseshave reduced other medical expenditure. These studies have used a variety of methodologies and kinds of data. Lichtenberg (2001) examined condition-by-patientlevel data from the 1996 Medical Expenditure Panel Survey. Lichtenberg (2006a) examined longitudinal state-level data from the period 1997-2003, and Lichtenberg (2007a) examined longitudinal disease-level data from the period 1990-2003. All three of these studies, which were based on U.S. data, provided support for the hypothesis that, overall, using newer drugs has reduced other types of medical expenditure, particularly hospital expenditure.

Other studies have examined specific classes of drugs. Miller et al (2005) investigated whether use of newer cardiovascular drugs reduced other medical expenditure. They concluded that there was no relationship between use of newer drugs and non-drug expenditure. However Lichtenberg (2006b) argued that their analysis had some serious flaws, and that their conclusions should be viewed with considerable skepticism. In particular, they controlled for factors that should not have been controlled for, and they controlled poorly for factors that should have been controlled for.

Weisfeldt and Zieman (2007) surveyed evidence from clinical trials about drug and device efficacy in the prevention and treatment of coronary artery disease and heart failure during the period 1970-2010. They concluded that pharmaceutical agents played a major role in prevention of atheroscierosis and its consequences (heart attack, stroke, and heart failure), and that the marked reduction in cardiovascular disease and its consequences was largely driven by the development and implementation of drugs for long-term use and by complicated and costly procedures and operations for acute disease management. Two other lessons that emerged from their survey of the clinical literature 
are worth noting here. First, the introduction of new drugs within a class may improve the health of the population, even if newer agents do not strictly dominate older agents (i.e., they are not superior for every patient), because not all members of the population benefit similarly from the use of specific agents in a particular drug class. ${ }^{1}$ Second, evidence from clinical trials showing the efficacy of a drug may first be published many years after the class was launched. For example, according to Weisfeldt and Zieman, evidence from clinical trials showing the efficacy of aldosterone antagonists for preventing and treating coronary heart disease was first published in 1999, 39 years after the first drug in the class (spironolactone) was approved by the FDA. ${ }^{2}$

This study will examine the effect of changes in the vintage distribution of cardiovascular system drugs on hospitalization and mortality due to cardiovascular disease using longitudinal country-level data. The vintage of a drug is defined as the year in which the drug was first sold anywhere in the world. The concept of vintage has hardly been used in health economics, but it is well established in both theoretical and empirical analysis in other areas of economics. ${ }^{3}$

We will use annual data on the utilization of over 1100 cardiovascular drugs (active ingredients) in 20 OECD countries during the period 1995-2004. Cardiovascular drugs comprise the largest therapeutic class of drugs, in terms of expenditure, in 13 key global markets IMS Health (2006). Heart disease was the most frequent cause of hospitalization in the U.S. in 1999 (Popovic and Hall (2001)).

Section I of this paper describes the econometric models that we will estimate. Data sources and descriptive statistics are discussed in Section II. Empirical results are

\footnotetext{
${ }^{1}$ Thus, the introduction of new statins might have benefited patients even though Zhou et al (2006) concluded from published statin randomized placebo-controlled trials that pravastatin, simvastatin, and atorvastatin, when used at their standard dosages, showed no statistically significant difference in their effect on long-term cardiovascular prevention. Moreover Cannon et al (2004) found that patients taking 80 milligrams of atorvastatin (launched in January 1997) were 16\% less likely to die, have a heart attack, undergo bypass or angioplasty surgery, or develop worsening chest pain than those taking 40 milligrams of pravastatin (launched in October 1989).

${ }^{2}$ The class includes just one other drug: eplerenone, which was approved by the FDA in 2002.

${ }^{3}$ See Boucekkine et al (2006) for a brief survey of the theoretical literature on vintage capital. Empirical studies by Hulten (1992), Bahk and Gort (1993), and Sakellaris and Wilson (2004) have demonstrated that the vintage of capital equipment has an important effect on productivity in manufacturing.
} 
presented in Section III. Implications of the estimates are considered in Section IV. The final section presents a summary.

\section{Methodology}

We will estimate models of the following form, using longitudinal country-level data:

$$
\ln Y_{i t}=\beta r r_{-} v_{i n t}+\gamma Z_{i t}+\alpha_{i}+\delta_{t}+\varepsilon_{i t}
$$

where

$\mathrm{Y}_{\text {it }}$ = a measure of hospital use or mortality due to cardiovascular disease in country i $(i=1, \ldots, 21)$ in year $t(t=1995, \ldots, 2003)$

rx_vint $_{i t}=$ a measure of the vintage distribution of cardiovascular system (ATC class C) drugs used in country $i$ in year $t$

$\mathrm{Z}_{\mathrm{it}} \quad=$ other potential determinants of hospital use or mortality due to cardiovascular disease in country $\mathrm{i}$ in year $\mathrm{t}$

$\alpha_{\mathrm{i}}=$ a fixed effect for country $\mathrm{i}$

$\delta_{\mathrm{t}}=$ a fixed effect for year $\mathrm{t}$

Since the model includes country and year fixed effects, it is a difference-in-differences model. Negative and significant estimates of $\beta$ would indicate that, ceteris paribus, countries with above-average increases in cardiovascular drug vintage had above-average declines (or below-average increases) in cardiovascular hospital use and mortality.

This model is static: it is predicated on the assumption that hospital use and mortality depend on contemporaneous values of drug vintage and other variables. In reality, health outcomes might depend on lagged as well as contemporaneous values of the explanatory variables. ${ }^{4}$ But there are two practical reasons to estimate a static model. First, the time-series is relatively short, since 1995 is the first year for which the drug data are available. Including lagged vintage would therefore significantly reduce the number of sample observations. Second, many of the explanatory variables exhibit high serial correlation. This makes precise identification of the lag structure challenging, and would cause multicollinearity if lagged as well as current values of regressors were included.

\footnotetext{
${ }^{4}$ Weisfeldt and Zieman (2007) observe that, unlike therapies used in infectious diseases, cardiovascular agents offer no rapid "cure." Rather, they prevent or reduce the progression of disease when ingested continuously.
} 


\section{Dependent variables}

We will estimate models of the following measures of hospital use or mortality due to cardiovascular disease:

- The number of hospital discharges ${ }^{5}$ in which the principal diagnosis was cardiovascular disease per 100,000 population (n_discharges)

- Average length of stay ${ }^{6}$ in hospital discharges in which the principal diagnosis was cardiovascular disease (alos)

- The number of hospital days in which the principal diagnosis was cardiovascular disease per 100,000 population (n_days $=$ n_discharges $*$ alos)

- The (age-standardized) number of deaths caused by diseases of the circulatory system $^{7}$ per 100,000 population (n_deaths)

- Potential years of life lost due to diseases of the circulatory system before age 70 per 100,000 population $^{8}$ (pyll)

\section{Measures of the vintage distribution of cardiovascular system drugs}

We will use two different measures of the vintage distribution of cardiovascular system drugs. Both are based on the following general definition of drug vintage:

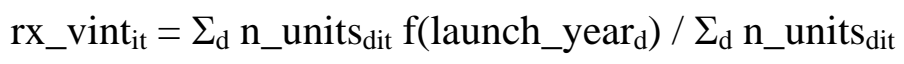

where

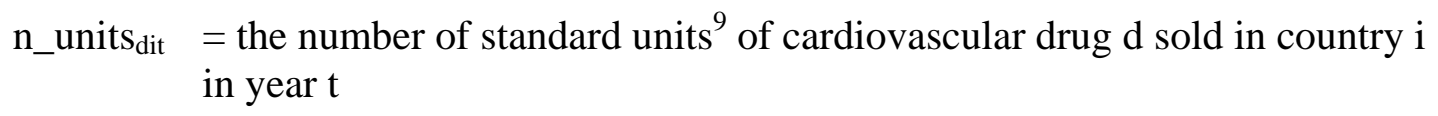

\footnotetext{
${ }^{5}$ Discharge is the formal release of an in-patient from an acute care institution after a period of "hospitalization". It includes deaths in hospitals, but excludes same-day separations and transfers to other care units within the same institution. However, the following countries include at least some same-day separations: Austria, Czech Republic, France, Hungary, New Zealand and the United States.

${ }^{6}$ Average length of stay (ALOS) is calculated by dividing the number of days stayed (from the date of admission in an in-patient institution) by the number of discharges (including deaths).

${ }^{7}$ The age-standardized number of deaths is calculated as the population times the age-standardized death rate. The latter is calculated by the OECD Secretariat, using the total OECD population for 1980 as the reference population. The age-standardized death rates are necessary for comparing the level of mortality across countries and over time since they take into account the differences in age structure of the populations.

${ }^{8}$ Potential years of life lost (PYLL) is a summary measure of premature mortality which provides an explicit way of weighting deaths occurring at younger ages, which are, a priori, preventable. The calculation of PYLL involves summing up deaths occurring at each age and multiplying this with the number of remaining years to live up to a selected age limit. The limit of 70 years has been chosen for the calculations in OECD Health Data. In order to assure cross- country and trend comparison, the PYLL are standardized for each country $i$ and each year $t$.

${ }^{9}$ A standard unit is equivalent to a standard dose of medication (Aldonas (2005)). Standard Units (SU) are determined by taking the number of counting units (e.g. actual number of $\mathrm{ml}$ in a bottle) and dividing it by
} 
launch_year $\mathrm{d}$ = the year of initial world launch of cardiovascular drug $\mathrm{d}$

The two measures are based on two different forms of the function f(launch_year ${ }_{\mathrm{d}}$ ):

$$
\begin{aligned}
\mathrm{f}_{1}\left(\text { launch_year }_{\mathrm{d}}\right) & =1 \mathrm{if} \text { launch_year } \\
& =0 \text { if launch_year }>1995 \\
\mathrm{f}_{2}\left(\text { launch_year }_{\mathrm{d}}\right) & =1995 \\
& =0 \text { if launch_year } \\
&
\end{aligned}
$$

The two corresponding measures of cardiovascular drug vintage are:

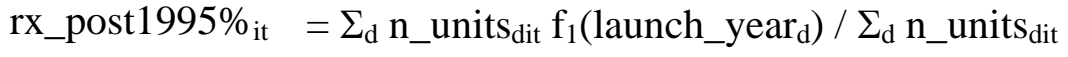

$$
\begin{aligned}
& =\text { the fraction of standard units whose active ingredients } \\
& \text { were launched after } 1995 \\
& \text { rx_post1990\% }{ }_{i t}=\Sigma_{\text {d }} \text { n_units }{ }_{\text {dit }} \mathrm{f}_{2}\left(\text { launch_year }_{\mathrm{d}}\right) / \Sigma_{\mathrm{d}} \text { n_units }{ }_{\text {dit }} \\
& =\text { the fraction of standard units whose active ingredients } \\
& \text { were launched after } 1990
\end{aligned}
$$

Other potential determinants of hospital use or mortality due to cardiovascular disease

In addition to cardiovascular drug vintage, the models of cardiovascular hospitalization and mortality we estimate will include several other types of explanatory variables: the quantity of cardiovascular medications consumed per person; indicators of the use of other medical innovations (CT scanners \& MRI units); indicators of potentially important cardiovascular risk factor (calories consumed per person per day and per capita expenditure on tobacco and alcohol); and demographic variables (population size \& age structure, income, and educational attainment). In particular, the models will include the following covariates:

$$
\begin{aligned}
\ln \left(\mathrm{n} \_\mathrm{cv} \_\mathrm{su}_{\mathrm{it}}\right) & =\text { the log of the number of standard units of cardiovascular drugs } \\
& \text { per person } \\
\ln \left(\mathrm{ct} \_\mathrm{scan}_{\mathrm{it}}\right) & =\text { the log of the number of computed tomography scanners per } \\
& \text { million population } \\
\ln \left(\mathrm{mri}_{\mathrm{it}}\right) & =\text { the log of the number of magnetic resonance imaging units per } \\
& \text { million population }
\end{aligned}
$$




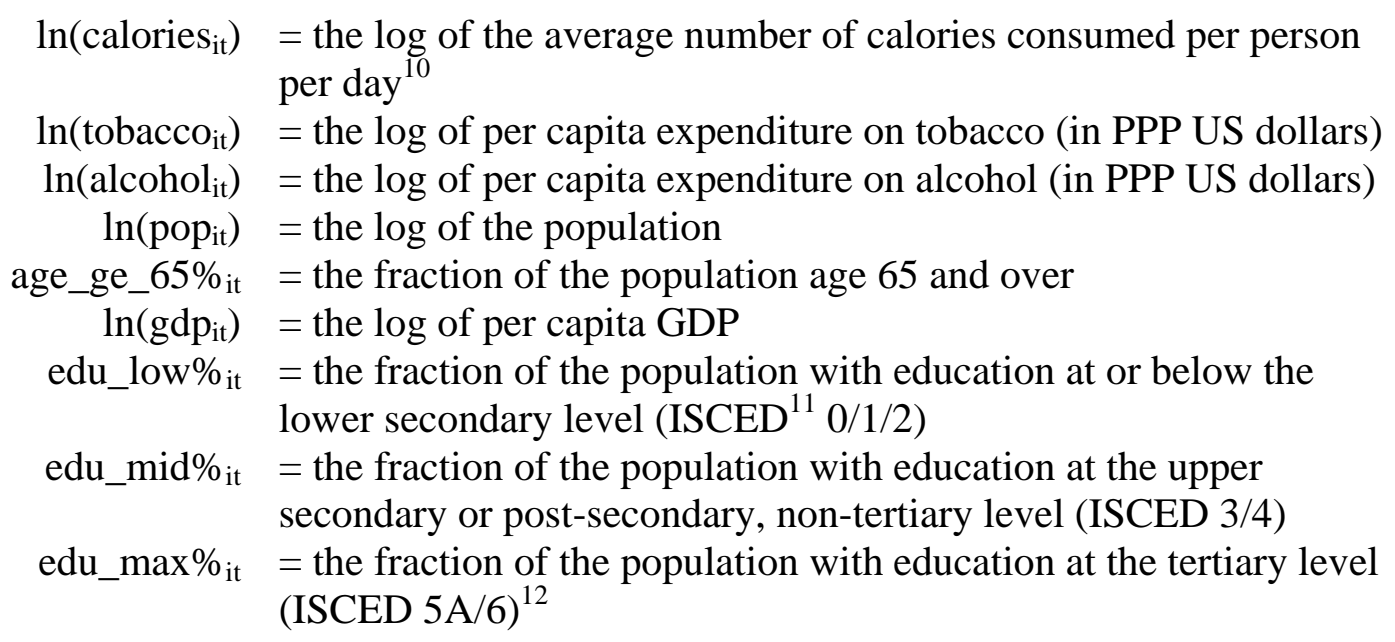

Cardiovascular disease prevalence. Ideally, we could control directly for the prevalence of cardiovascular disease, i.e. the fraction of the population at risk for cardiovascular hospitalization or death. Unfortunately, reliable data on the prevalence of cardiovascular disease, by country and year, are not available. ${ }^{13}$ The cardiovascular drug utilization rate (n_cv_su) may control, to some extent, for the cardiovascular disease prevalence rate, but it also reflects intensity of use among people with the disease:

$$
\mathrm{n} \_\mathrm{cV} \_\mathrm{su}=\underset{\text { prev }}{\mathrm{su}} \times \frac{\text { prev }}{\text { pop }}
$$

An increase in the cardiovascular disease prevalence rate (prev / pop) would increase cardiovascular hospitalization and mortality, but an increase in treatment intensity (su / prev) might be expected to reduce cardiovascular hospitalization and mortality. Hence, the net effect of an increase in per capita consumption of cardiovascular drugs on cardiovascular hospitalization and mortality is theoretically ambiguous. As indicated

\footnotetext{
${ }^{10}$ The main data source is the Food and Agriculture Organization of the United Nations Nutrition database (FAOSTAT). See http://faostat.fao.org/.

${ }^{11}$ ISCED denotes the International Standard Classification of Education from 1997. ISCED 5B (programs at the tertiary level that focus on practical, technical or occupational skills for direct entry into the labor market) is the omitted category.

${ }^{12}$ The omitted education category is the fraction of the population with education at the ISCED 5B level. These programs are typically shorter than those of ISCED 5A and focus on practical, technical or occupational skills for direct entry into the labor market, although some theoretical foundations may be covered in the respective programs. They have a minimum duration of two years full-time equivalent at the tertiary level.

${ }^{13}$ HIV/AIDS and cancer are the only chronic diseases for which there are reasonably reliable longitudinal estimates of disease prevalence, due to the existence of disease registries. Lichtenberg (2006c, 2007b) uses these data to investigate the effects of pharmaceutical use and innovation on the survival rates of HIV/AIDS and cancer patients in the U.S.
} 
above, we also control for per capita income and educational attainment, which may influence both disease prevalence and the quality of disease management, hence the rate of cardiovascular hospitalization and mortality.

Cardiovascular risk factors. Instead of, or in addition to, controlling for cardiovascular disease prevalence, it is desirable to control for cardiovascular disease risk factors. Advanced age, obesity and smoking are known to be cardiovascular disease risk factors. Our models of hospital utilization will control for the fraction of the population age 65 and over. ${ }^{14}$ The OECD Health Data 2006 database contains some information about the prevalence of obesity and tobacco use. Unfortunately, the data on these indicators are quite incomplete. For example, data on obesity are available for only 37\% (59 out of 159) of the country-year observations in our sample; data on tobacco use were available for $57 \%$ (91 out of 159) of the observations. Including a measure of obesity in the model would reduce the number of residual degrees of freedom by 83\% (from 111 to 19). Therefore the basic models we estimate will not include measures of obesity. However we will control for an important (and frequently reported) determinant of obesity: calories consumed per person per day. We will also control for per capita expenditure (in PPP US dollars) on tobacco and on alcohol; data on these variables were obtained from the $O E C D$ Annual National Accounts database.

Other medical innovation. Weisfeldt and Zieman (2007) found that the marked reduction in cardiovascular disease and its consequences was largely driven by complicated and costly procedures and operations for acute disease management as well as by the development and implementation of drugs for long-term use. It would therefore be ideal to control for the rate of adoption of non-pharmaceutical as well as pharmaceutical medical innovations relevant to cardiovascular disease.

The OECD Health Data 2006 database contains five indicators of nonpharmaceutical medical technology. Data on all of these indicators are quite incomplete. We will control for the use of two medical technologies: CT scanners and MRI units. These are the two technologies with the least incomplete data, and that are most relevant

\footnotetext{
${ }^{14}$ Our models of cardiovascular mortality will not control for the fraction of the population age 65 and over, because the mortality measures are age-adjusted.
} 
to the diagnosis and treatment of cardiovascular disease. ${ }^{15}$ Over 73,000 articles in MEDLINE refer to both “Cardiovascular Diseases” and either “Tomography, X-Ray Computed” or "Magnetic Resonance Imaging”. 16 However CT scanners and MRI units are also used to diagnose many other diseases. These measures may not adequately control for non-pharmaceutical cardiovascular disease innovation.

If pharmaceutical and non-pharmaceutical cardiovascular disease innovation are “complements” (i.e., they are positively correlated across countries), estimates of $\beta$ could be biased away from zero. On the other hand, if pharmaceutical and non-pharmaceutical innovation are "substitutes” (i.e., they are negatively correlated across countries), estimates of $\beta$ could be biased towards zero. It is not possible to determine the sign of the correlation between pharmaceutical and non-pharmaceutical cardiovascular disease innovation across countries, but it is possible to determine the sign of this correlation across U.S. states. Using data on the two largest public health insurance programs, we constructed the following indicators of the adoption of pharmaceutical and nonpharmaceutical (i.e. surgical) cardiovascular disease innovations by state in 2004:

\begin{tabular}{|c|c|}
\hline rx_post1995\% $\%_{s, 2004}$ & $\begin{array}{l}=\text { the fraction of Medicaid }^{17} \text { cardiovascular drug } \\
\text { prescriptions in state s in } 2004 \text { whose active } \\
\text { ingredients were approved by the FDA after } 1995\end{array}$ \\
\hline rx_post $1990 \% \%_{s, 2004}$ & $\begin{array}{l}=\text { the fraction of Medicaid cardiovascular drug } \\
\text { prescriptions in state s in } 2004 \text { whose active } \\
\text { ingredients were approved by the FDA after } 1990\end{array}$ \\
\hline surg_post $1995 \%$ s,2004 & $\begin{array}{l}=\text { the fraction of Medicare major cardiovascular } \\
\text { surgical procedures }{ }^{18} \text { in state s in } 2004 \text { with } \\
\text { procedure codes established by the American } \\
\text { Medical Association after } 1995\end{array}$ \\
\hline surg_post $1990 \% \%_{s, 2004}$ & $\begin{array}{l}=\text { the fraction of Medicare major cardiovascular } \\
\text { surgical procedures in state s in } 2004 \text { with }\end{array}$ \\
\hline
\end{tabular}

\footnotetext{
${ }^{15}$ The other three technologies are radiation therapy equipment, lithotriptors, and mammographs.

${ }^{16}$ See, for example, Harrigan et al (2008) and Schmid et al (2008).

${ }^{17}$ Medicaid is a health insurance program available only to certain low-income individuals and families who fit into an eligibility group that is recognized by federal and state law. There were about 82 million Medicaid cardiovascular drug prescriptions in 2004.

${ }^{18}$ Medicare is a health insurance program for people age 65 or older, people under age 65 with certain disabilities, and people of all ages with End-Stage Renal Disease (permanent kidney failure requiring dialysis or a kidney transplant). There were about 4 million Medicare major cardiovascular procedures performed in 2004. Major cardiovascular surgical procedures are procedures with Berenson-Eggers Type of Service (BETOS) codes P2A through P2F, i.e CABG, aneurysm repair, thromboendarterectomy, coronary angioplasty (PTCA), pacemaker insertion, and other major cardiovascular procedures. See http://www.cms.hhs.gov/hcpcsreleasecodesets/20_betos.asp.
} 
procedure codes established by the American

Medical Association after 1990

The data used to construct these measures were obtained from a number of sources. ${ }^{19}$ As discussed in Lichtenberg (2007b), the surgery innovation measures are probably less reliable than the drug innovation measures, because FDA approval of a drug is a more meaningful indicator than AMA establishment of a new surgical procedure code. In particular, some procedures with "new” procedure codes may be just relabeled or reclassified old procedures, rather than true innovations.

The following table shows the correlations across states $(\mathrm{N}=50)$ between the pharmaceutical and surgical innovation measures, both unweighted and weighted by the number of prescriptions (n_rx) or the number of major surgical procedures (n_proc):

\begin{tabular}{|l|c|c|c|}
\hline & unweighted & weight=n_rx & weight=n_proc \\
\hline corr(rx_post1990, surg_post1990) & -0.129 & -0.213 & -0.180 \\
\hline p-value & 0.378 & 0.142 & 0.217 \\
\hline & & & \\
\hline corr(rx_post1995, surg_post1995) & -0.229 & -0.473 & -0.257 \\
\hline p-value & 0.113 & 0.001 & 0.075 \\
\hline
\end{tabular}

All six correlation coefficients are negative, and one is highly significant. This suggests that, within the U.S., pharmaceutical and non-pharmaceutical cardiovascular disease innovation may be substitutes rather than complements. Therefore, failure to control adequately for non-pharmaceutical cardiovascular disease innovation is more likely to bias estimates of $\beta$ towards zero than away from zero.

\footnotetext{
${ }^{19}$ State-level data on Medicaid cardiovascular drug prescriptions were obtained from Medicaid State Drug Utilization Files (http://www.cms.hhs.gov/MedicaidDrugRebateProgram/SDUD/List.asp). Data on FDA approval dates were obtained from the Drugs@FDA database (http://www.fda.gov/cder/drugsatfda/datafiles/default.htm). State-level data on Medicare major cardiovascular surgical procedures were obtained from the Physician/Supplier Procedure Summary Master File (http://www.cms.hhs.gov/NonIdentifiableDataFiles/06 PhysicianSupplierProcedureSummaryMasterFile.asp). Data on the dates at which procedure codes were established by the American Medical Association were obtained from the AMA’s Current Procedural Terminology Assistant Archives (https://catalog.amaassn.org/Catalog/product/product_detail.jsp?childName=\&parentCategoryName=\&parentCategory=\&productId=prod7 $\underline{\text { 80015\&category Name }=\text { \&prodId }=\text { \&start }=\text { \&parentId }=\text { ). }}$
} 


\section{Data sources and descriptive statistics}

Data on cardiovascular drug use (number of standard units), by pharmaceutical subclass, active ingredient, country, and year, were provided by IMS Health. There are over 1100 ingredients in 29 subclasses in ATC C. About 1.5 trillion standard units were sold in all classes combined in the 21 countries during 1995-2005. Table 1 shows illustrative data, by ingredient, for one subclass (C10A cholesterol \& triglyceride regulators) in one country (the U.S.) in one year (2005).

The 'launch date' is the date when a product was first made available to the market (although there are circumstances when the launch date is considered to be the date when the first pack was included in the IMS data, or first accrued sales). The world launch date of some ingredients is unknown. Many of these ingredients are naturally occurring. The fraction of standard units with missing launch dates declined from 12\% in 1995 to $6 \%$ in 2005.

Two features of the data are worth noting. First, a given ingredient may appear in several subclasses. Second, a given product may contain several ingredients. To avoid giving too much weight to combination products when calculating mean vintage, we used a two-step procedure to calculate mean vintage. First, we used the ingredient-level data to calculate mean vintage in each subclass, country, and year. Then, we used the subclass-level data to calculate mean vintage in each country and year, weighting by the number of sub-class SUs (not the sum of the number of ingredient SUs within the subclass).

The mean vintage of cardiovascular drugs varies considerably across countries. Figure 1 shows post-1995 SUs as a percentage of total SUs in 2004, by country. In the top 5 countries, at least $13 \%$ of SUs were post-1995 SUs. In the bottom 4, only $1 \%$ of SUs were post-1995 SUs. It is not surprising that these are the emerging economies of Eastern Europe. However there are also sharp differences in cardiovascular drug vintage between countries that are otherwise similar. Switzerland's post-1995 share (11\%) is more than twice as high as Austria's (5\%). Australia's post-1995 share (20\%) is four times as large as New Zealand's (5\%). Table 2 further documents these differences by 
showing the top 10 (ranked by number of SUs) cardiovascular drugs in these four countries in 2005. Descriptive statistics for all variables are shown in Table 3.

\section{Empirical results}

Estimates of eq. (1) based on the first measure of cardiovascular drug vintage (rx_post1995\%, the fraction of standard units whose active ingredients were launched after 1995) are shown in Table 4. Estimates based on the second measure of cardiovascular drug vintage (rx_post1990\%) are shown in Table 5.

First we will discuss the estimates shown in Table 4. In model 1, the dependent variable is the log of the number of cardiovascular disease hospital discharges per 100,000 population. The rx_post1995\% coefficient is negative and highly significant (pvalue $<.0001$ ). This signifies that countries with larger increases in the share of cardiovascular drug SUs that were post-1995 SUs had smaller increases in the cardiovascular disease hospital discharge rate, ceteris paribus.

The coefficient on per capita cardiovascular drug use is not significantly different from zero. As noted above, the net effect of an increase in per capita consumption of cardiovascular drugs on cardiovascular hospitalization is theoretically ambiguous.

Coefficients on four of the covariates are statistically significant (p-value $<.05$ ). The coefficient on age_ge_65\% is positive and significant, as one would expect: cardiovascular hospital utilization increases when the fraction of the population that is elderly rises. The coefficient on the log of the number of CT scanners per million population is also positive and significant. This is consistent with the view that some diagnostic innovations may increase utilization of hospital care. ${ }^{20}$ Increased consumption of tobacco is also positively associated with cardiovascular hospital utilization, but calorie consumption is inversely related to cardiovascular hospital utilization.

The dependent variable in model 2 is the log of average length of cardiovascular disease hospital stays. Once again, the rx_post1995\% coefficient is negative and significant ( $\mathrm{p}$-value $=.03$ ). This implies that using newer drugs has reduced average

\footnotetext{
${ }^{20}$ The Kaiser Family Foundation (2007), citing Rettig (1994), says that "advances in medical technology have contributed to rising overall U.S. health care spending.”
} 
length of stay. The coefficient on GDP is also negative and significant: average length of stay has declined faster in countries with higher growth in per capita GDP. Length of stay is positively correlated with calorie and alcohol consumption, but negatively correlated with tobacco consumption. The fact that the coefficient on edu_max\% is positive and significant suggests that ALOS has declined more slowly in countries where the fraction of the population that is highly educated has increased the most. ${ }^{21}$ However the implied effect of education on ALOS is quite small: if the entire population shifted from the low education to the maximum education category, ALOS would increase by less than $4 \%$.

The dependent variable in model 3 is the log of the number of hospital days in which the principal diagnosis was cardiovascular disease per 100,000 population. The coefficients in model 3 are equal to the sums of the coefficients in models 1 and 2. Once again, the rx_post1995\% coefficient is negative and highly significant. The only other variables whose coefficients are significant are ln(ct_scan), age_ge_65\%, and edu_max\%.

The dependent variable in model 4 is the (age-standardized) number of deaths caused by diseases of the circulatory system per 100,000 population. The drug vintage coefficient is also negative and highly significant $(\mathrm{p}$-value $=.0059)$ in this model. This implies that using newer cardiovascular drugs has reduced the age-adjusted cardiovascular disease mortality rate. The coefficient on per capita drug consumption is positive and significant. Presumably this is because increased per capita cardiovascular drug consumption is indicative of increased cardiovascular disease prevalence. The coefficient on $\ln$ (calories) is positive and significant at the $10 \%$ level. This may reflect the effect of obesity on cardiovascular mortality. The education coefficients are significant, but the implied effect of changes in the educational attainment distribution on cardiovascular mortality is quite small.

The dependent variable in model 5 is the log of the number of potential years of life lost due to cardiovascular disease before age 70 per 100,000 population. This measure gives a great deal of weight to deaths that occur well before the age of 70 , and

\footnotetext{
${ }^{21}$ Lichtenberg (2007c) finds a positive association across U.S. states between per capita hospital expenditure growth and growth in educational attainment during the period 1991-2004, controlling for a number of other factors.
} 
no weight to deaths that occur after the age of 70 . This is the only model in which the drug vintage coefficient is not statistically significant.

To summarize, estimates based on one measure of cardiovascular drug vintagethe fraction of standard units whose active ingredients were launched after 1995—are consistent with the hypothesis that use of newer cardiovascular drugs has reduced the number of cardiovascular hospital discharges, average length of stay, and hospital days. The estimates also indicate that use of newer cardiovascular drugs has reduced the ageadjusted cardiovascular mortality rate, but not the number of potential years of life lost due to cardiovascular disease before age 70 per 100,000 population. Table 5 shows that similar results are obtained when we use an alternative measure of cardiovascular drug vintage - the fraction of standard units whose active ingredients were launched after 1990.

\section{Implications of the estimates}

During the period 1995-2004, the mean vintage of cardiovascular drugs increased: the mean fraction of post-1995 drugs increased from $0.0 \%$ to $9.6 \%$, and the mean fraction of post-1990 drugs increased from $1.4 \%$ to $14.7 \%$. The vintage coefficient estimates presented in Tables 4 and 5 imply that this increase in vintage reduced the cardiovascular hospitalization rate, length of stay, and age-adjusted mortality. In other words, if drug vintage had not increased during 1995-2004, the number of hospital discharges, hospital days, and deaths would have been higher in 2004. The magnitudes of the implied increases are shown in Table 6. The two vintage measures yield similar estimates of the increase in the number of discharges in 2004 had there been no increase in vintage after 1995. The mean of these estimates is $51 \%$. The mean estimate of the increase in average length of stay is $12 \%$, and of the increase in hospital days is $70 \%$.

We estimate that per capita expenditure for cardiovascular hospital stays would have been $\$ 89$ higher in 2004 had drug vintage not increased during 1995-2004. This is how we derived this estimate. In 2004, mean per capita expenditure on hospital care for all diagnostic categories in OECD countries was $\$ 926$. We estimate that cardiovascular 
hospitalizations account for about $14 \%$ of total hospital expenditure. ${ }^{22}$ Hence mean per capita expenditure on cardiovascular hospital care in OECD countries was $\$ 128$ (= 14\% * \$926). The vintage coefficient estimates imply that, absent the 1995-2004 increase in drug vintage, there would have been 70\% more cardiovascular hospital days in 2004. Hence per capita expenditure for cardiovascular hospital stays would have been \$89 (= $70 \% * \$ 128$ ) higher had drug vintage not increased.

It is reasonable to expect that per capita expenditure on cardiovascular drugs would have been lower in 2004 had drug vintage not increased during 1995-2004. The OECD Health Data 2006 database contains some information on sales of pharmaceutical products by selected Anatomic Therapeutic Chemical (ATC) groups, based on retail prices. In particular, it contains information about per capita sales of cardiovascular system drugs, in U.S. PPP dollars. To assess the effect of cardiovascular drug vintage on per capita expenditure on cardiovascular drugs, we estimated the following model:

$$
\ln \left(\text { cardio_rx_expend } d_{i t}\right)=\pi \text { rx_vint }{ }_{i t}+\gamma \ln \left(n \_c v \_s u_{i t}\right)+\alpha_{i}+\delta_{t}+\varepsilon_{i t}
$$

Estimates of $\pi$ based on the two different drug vintage measures are shown in Table 7. Both estimates are positive and significant, as one would expect: countries with larger increases in the share of SUs that were for post-1995 or post-1990 drugs had larger increases in per capita drug expenditure, conditional on growth in the number of SUs per capita.

To be conservative, we will use the larger (more negative) estimate of the reduction in 2004 per capita drug expenditure that would have occurred had drug vintage not increased after 1995: 25.1\%. Mean per capita expenditure on all prescription drugs in OECD countries was \$477 in 2004. Cardiovascular drug expenditure accounted for about $20 \%$ of total drug expenditure, so per capita expenditure on cardiovascular drugs in OECD countries was $\$ 95(=20 \% * \$ 477)$ in 2004 . The more conservative estimate implies that per capita cardiovascular drug expenditure would have been $\$ 24(=25.1 \%$ * \$95) lower in 2004 had drug vintage not increased after 1995. Our estimate of the increase in per capita expenditure for cardiovascular hospital stays that would occurred

\footnotetext{
${ }^{22}$ Cardiovascular hospitalizations account for about $14 \%$ of total hospital bed days.
} 
had drug vintage not increased (\$89) is about 3.7 times as large as our estimate of the reduction in per capita expenditure for cardiovascular drugs that would have occurred (\$24).

\section{Summary}

This study has examined the effect of changes in the vintage distribution of cardiovascular system drugs on hospitalization and mortality due to cardiovascular disease using longitudinal country-level data on 20 OECD countries during the period 1995-2003.

Countries with larger increases in the share of cardiovascular drug SUs that were post-1995 SUs had smaller increases in the cardiovascular disease hospital discharge rate, controlling for the quantity of cardiovascular medications consumed per person, the use of other medical innovations (CT scanners \& MRI units), consumption of calories, tobacco, and alcohol, and demographic variables (population size \& age structure, income, and educational attainment). The estimates also indicate that use of newer cardiovascular drugs has reduced average length of stay and the age-adjusted cardiovascular mortality rate, but not the number of potential years of life lost due to cardiovascular disease before age 70 per 100,000 population.

The estimates indicate that if drug vintage had not increased during 1995-2004, hospitalization and mortality would have been higher in 2004. We estimate that per capita expenditure on cardiovascular hospital stays would have been 70\% (\$89) higher in 2004 had drug vintage not increased during 1995-2004. Per capita expenditure on cardiovascular drugs would have been lower in 2004 had drug vintage not increased during 1995-2004. But our estimate of the increase in expenditure on cardiovascular hospital stays is about 3.7 times as large as our estimate of the reduction in per capita expenditure for cardiovascular drugs that would have occurred (\$24).

Although our data on hospital use and especially on drug utilization were quite complete and reliable, data on cardiovascular risk factors were less complete. We can think of little reason to expect these risk factors to be correlated with drug vintage, conditional on income, education, and average rate of drug utilization (which we control 
for). Nevertheless, obtaining better information on these risk factors would certainly be desirable. 


\section{References}

Aldonas, Grant D. (2005), "Pharmaceutical Price Controls in OECD Countries, Implications for American Consumers, Pricing, Research and Development, and Innovation,” Testimony of Under Secretary for International Trade, U.S. Department of Commerce Before the Committee on Health, Education, Labor and Pensions, U.S. Senate, Washington, D.C., February 17, http://www.ita.doc.gov/media/Speeches/0205/aldonas_021705.html, accessed 10 January 2008.

Bahk, Byong-Hyong and Michael Gort (1993), "Decomposing Learning by Doing in New Plants,” Journal of Political Economy, 101, 561-583.

Boucekkine, Raouf, David de la Croix, and Omar Licandro, "Vintage Capital," Department of Economics, European University Institute, Eco No. 2006/08 http://cadmus.iue.it/dspace/bitstream/1814/4346/1/ECO2006-8.pdf, accessed 10 January 2008.

Cannon, Christopher P., et al (2004), “Intensive versus Moderate Lipid Lowering with Statins after Acute Coronary Syndromes,” New England Journal of Medicine 350 (15), 1495-1504, April 8.

Harrigan CJ. Appelbaum E. Maron BJ. Buros JL. Gibson CM. Lesser JR. Udelson JE. Manning WJ. Maron MS. Significance of papillary muscle abnormalities identified by cardiovascular magnetic resonance in hypertrophic cardiomyopathy. American Journal of Cardiology. 101(5):668-73, 2008 Mar 1.

Hulten, Charles R. (1992), "Growth accounting when technical change is embodied in capital,” The American Economic Review, Vol. 82, No. 4. (Sep., 1992), pp. 964-980.

IMS Health (2006), IMS Retail Drug Monitor, Tracking 13 Key Global Pharma Markets, 12 months to December 2006, http://www.imshealth.com/ims/portal/front/indexC/0,2773,6599_41382715_0,00.html, accessed 10 January 2008.

Kaiser Family Foundation (2007), "How Changes in Medical Technology Affect Health Care Costs,” March, http://www.kff.org/insurance/snapshot/chcm030807oth.cfm\#front5, accessed 10 January 2008.

Lichtenberg, Frank (2001), “Are the Benefits of Newer Drugs Worth Their Cost?

Evidence from the 1996 MEPS,” Health Affairs 20(5), September/October 2001, 241-51.

Lichtenberg, Frank (2006a). “The effect of using newer drugs on admissions of elderly Americans to hospitals and nursing homes: state-level evidence from 1997-2003,”

Pharmacoeconomics 24 Suppl 3:5-25. 
Lichtenberg, Frank (2006b). "On 'New Cardiovascular Drugs: Pattern of Use and Association with Non-Drug Health Expenditures'”. Inquiry. 2006 Spring; 43(1): 80-2.

Lichtenberg, Frank (2006c), “The impact of increased utilization of HIV drugs on longevity and medical expenditure: an assessment based on aggregate U.S. time-series data," Expert Review of Pharmacoeconomics and Outcomes Research, Volume 6, Number 4, August, 425-436.

Lichtenberg, Frank (2007a), "The impact of new drugs on US longevity and medical expenditure, 1990-2003: Evidence from Longitudinal, Disease-Level data,” American Economic Review 97 (2), May, 438-443.

Lichtenberg, Frank (2007b), "Pharmaceutical Innovation and U.S. Cancer Survival, 1992-2003: Evidence from Linked SEER-MEDSTAT Data," Forum for Health Economics \& Policy: Vol. 10: Iss. 1 (Frontiers in Health Policy Research), Article 1. http://www.bepress.com/fhep/10/1/1

Lichtenberg, Frank (2007c), "Why Has Longevity Increased More in Some States than in Others? The Role of Medical Innovation and Other Factors," Manhattan Institute for Policy Research, Medical Progress Report No. 4, July, http://www.manhattaninstitute.org/html/mpr_04.htm, accessed 10 January 2008.

Miller GE, Moeller JF, Stafford RS (2005). "New cardiovascular drugs: patterns of use and association with non-drug health expenditures.” Inquiry. 2005-2006 Winter; 42(4): 397-412.

Popovic JR, and MJ Hall (2001), "1999 National Hospital Discharge Survey. Advance data from vital and health statistics," no 319. Hyattsville, Maryland: National Center for Health Statistics. http://www.cdc.gov/nchs/data/ad/ad319.pdf, accessed 10 January 2008.

Rettig, Richard A. (1994), "Medical Innovation Duels Cost Containment," Health Affairs (Summer): 15.

Sakellaris, Plutarchos and Dan Wilson (2004), "Quantifying Embodied Technological Change,” Review of Economic Dynamics 7(1), pp. 1-26.

Schmid M. Achenbach S. Ropers D. Komatsu S. Ropers U. Daniel WG. Pflederer T. Assessment of changes in non-calcified atherosclerotic plaque volume in the left main and left anterior descending coronary arteries over time by 64-slice computed tomography. American Journal of Cardiology. 101(5):579-84, 2008 Mar 1.

Weisfeldt, ML, and SJ Zieman (2007), "Advances in the prevention and treatment of cardiovascular disease,” Health Affairs 26(1), Jan-Feb, 25-37. 
Zhou Z, E Rahme, and L Pilote (2006). "Are statins created equal? Evidence from randomized trials of pravastatin, simvastatin, and atorvastatin for cardiovascular disease prevention". Am. Heart J. 151 (2): 273-81. 
Table 1

Number of standard units of cholesterol \& triglyceride regulator agents sold in the U.S. in 2005 , by active ingredient

\begin{tabular}{|l|r|r|}
\hline subclass/ingredient & world launch & $\begin{array}{c}\text { month/year } \\
\text { thousands of } \\
\text { standard } \\
\text { units }\end{array}$ \\
\hline C1OA cholesterol \& triglyceride regulator & & $8,464,846$ \\
\hline ATORVASTATIN & $1 / 1997$ & $3,144,330$ \\
\hline SIMVASTATIN & $6 / 1988$ & $1,555,881$ \\
\hline GEMFIBROZIL & $2 / 1982$ & 548,762 \\
\hline EZETIMIBE & $11 / 2002$ & 539,047 \\
\hline LOVASTATIN & $9 / 1987$ & 525,054 \\
\hline PRAVASTATIN & $10 / 1989$ & 493,161 \\
\hline FENOFIBRATE & $4 / 1975$ & 428,381 \\
\hline NICOTINIC ACID & & 366,023 \\
\hline ROSUVASTATIN & $2 / 2003$ & 343,580 \\
\hline COLESEVELAM & $9 / 2000$ & 193,975 \\
\hline FLUVASTATIN & $2 / 1994$ & 182,766 \\
\hline COLESTYRAMINE & $4 / 1967$ & 96,573 \\
\hline COLESTIPOL & $3 / 1977$ & 47,313 \\
\hline ACETYLSALICYLIC ACID & $1 / 1910$ & 213 \\
\hline ALLIUM SATIVUM & $1 / 1919$ & 0 \\
\hline ASCORBIC ACID & & 0 \\
\hline CERIVASTATIN & & 0 \\
\hline CLOFIBRATE & & 0 \\
\hline DEXTROTHYROXINE & & 0 \\
\hline GLYCINE MAX & & 0 \\
\hline LECITHIN & & 0 \\
\hline NICOTINAMIDE & & 0 \\
\hline PROBUCOL & & 0 \\
\hline PYRIDOXINE & & 0 \\
\hline RIBOFLAVIN & & 0 \\
\hline THIAMINE & & 0 \\
\hline VITAMIN E & & 0 \\
\hline & & 0 \\
\hline
\end{tabular}


Figure 1

Post-1995 cardiovascular Standard Units (Sus) as a percentage of total SUs in 2004, by country

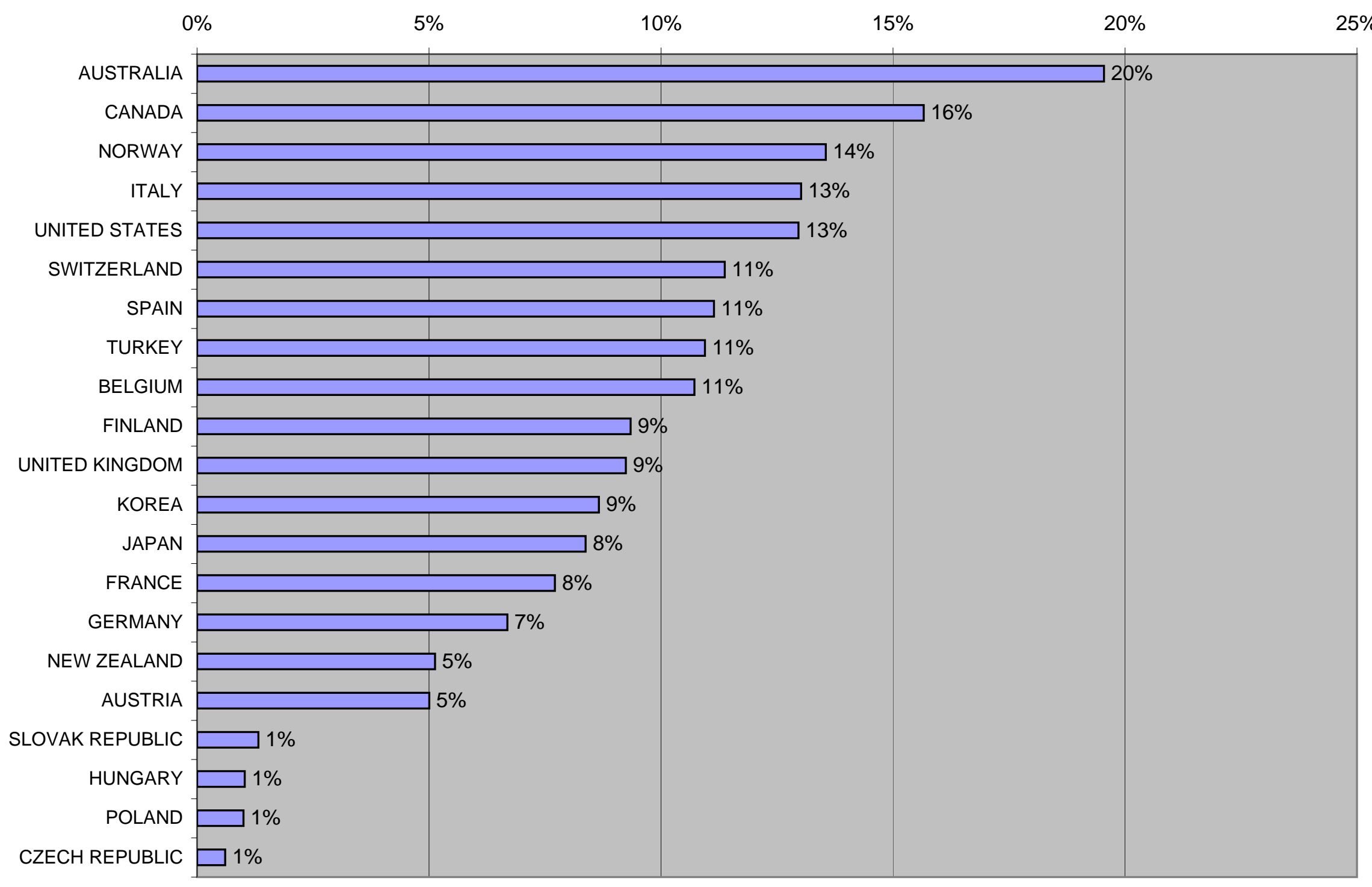


Table 2

Top 10 (ranked by no. of standard units) cardiovascular drugs in 4 countries in 2005

\begin{tabular}{|c|c|c|c|c|c|c|c|}
\hline molecule & $\begin{array}{l}\text { launch } \\
\text { year }\end{array}$ & $\begin{array}{l}\% \text { of } \\
\text { std } \\
\text { units }\end{array}$ & class & molecule & \begin{tabular}{|l|} 
launch \\
year
\end{tabular} & $\begin{array}{l}\% \text { of } \\
\text { std } \\
\text { units }\end{array}$ & class \\
\hline \multicolumn{4}{|c|}{ AUSTRALIA $(\mathrm{N}=2,997,258)$} & \multicolumn{4}{|c|}{ NEW ZEALAND $(\mathrm{N}=620,001)$} \\
\hline ATORVASTATIN & 1997 & $9 \%$ & \begin{tabular}{|l|} 
C10A \\
CHOLEST\&TRIGLY.R \\
EGULATOR
\end{tabular} & SIMVASTATIN & 1988 & $14 \%$ & $\begin{array}{l}\text { C10A } \\
\text { CHOLEST\&TRIGLY.RE } \\
\text { GULATOR }\end{array}$ \\
\hline SIMVASTATIN & 1988 & $5 \%$ & \begin{tabular}{|l|} 
C10A \\
CHOLEST\&TRIGLY.R \\
EGULATOR
\end{tabular} & METOPROLOL & 1975 & $8 \%$ & $\begin{array}{l}\text { C7A B-BLOCKING } \\
\text { AGENTS,PLAIN }\end{array}$ \\
\hline $\begin{array}{l}\text { HYDROCHLOROT } \\
\text { HIAZIDE }\end{array}$ & 1959 & $5 \%$ & $\begin{array}{l}\text { C9D ANGIOTEN-II } \\
\text { ANTAG, COMB }\end{array}$ & QUINAPRIL & 1989 & $7 \%$ & $\begin{array}{l}\text { C9A ACE INHIBITORS } \\
\text { PLAIN }\end{array}$ \\
\hline FUROSEMIDE & 1964 & $4 \%$ & C3A DIURETICS & NITROGLYCERIN & 1915 & $6 \%$ & $\begin{array}{l}\text { C1E NITRITES AND } \\
\text { NITRATES }\end{array}$ \\
\hline IRBESARTAN & 1997 & $4 \%$ & $\begin{array}{l}\text { C9C ANGIOTEN-II } \\
\text { ANTAG, PLAIN }\end{array}$ & FUROSEMIDE & 1964 & $6 \%$ & C3A DIURETICS \\
\hline PERINDOPRIL & 1988 & $4 \%$ & $\begin{array}{l}\text { C9A ACE } \\
\text { INHIBITORS PLAIN }\end{array}$ & $\begin{array}{l}\text { BENDROFLUMET } \\
\text { HIAZIDE }\end{array}$ & 1957 & $6 \%$ & C3A DIURETICS \\
\hline ATENOLOL & 1976 & $4 \%$ & $\begin{array}{l}\text { C7A B-BLOCKING } \\
\text { AGENTS,PLAIN }\end{array}$ & CILAZAPRIL & 1986 & $6 \%$ & $\begin{array}{l}\text { C9A ACE INHIBITORS } \\
\text { PLAIN }\end{array}$ \\
\hline RAMIPRIL & 1989 & $4 \%$ & $\begin{array}{l}\text { C9A ACE } \\
\text { INHIBITORS PLAIN }\end{array}$ & FELODIPINE & 1988 & $4 \%$ & $\begin{array}{l}\text { C8A CALCIUM } \\
\text { ANTAGONIST PLAIN }\end{array}$ \\
\hline METOPROLOL & 1975 & $3 \%$ & $\begin{array}{l}\text { C7A B-BLOCKING } \\
\text { AGENTS,PLAIN }\end{array}$ & DILTIAZEM & 1974 & $4 \%$ & $\begin{array}{l}\text { C8A CALCIUM } \\
\text { ANTAGONIST PLAIN }\end{array}$ \\
\hline NITROGLYCERIN & 1915 & $3 \%$ & $\begin{array}{l}\text { C1E NITRITES AND } \\
\text { NITRATES }\end{array}$ & $\begin{array}{l}\text { HYDROCHLOROT } \\
\text { HIAZIDE }\end{array}$ & 1959 & $3 \%$ & $\begin{array}{l}\text { C9B ACE INHIBITORS } \\
\text { COMBINAT }\end{array}$ \\
\hline & & & & & & & \\
\hline \multicolumn{4}{|c|}{ SWITZERLAND $(\mathrm{N}=1,903,135)$} & \multicolumn{4}{|c|}{ AUSTRIA $(\mathrm{N}=1,890,382)$} \\
\hline $\begin{array}{l}\text { HYDROCHLOROT } \\
\text { HIAZIDE }\end{array}$ & 1959 & $3 \%$ & $\begin{array}{l}\text { C9D ANGIOTEN-II } \\
\text { ANTAG, COMB }\end{array}$ & $\begin{array}{l}\text { HYDROCHLOROT } \\
\text { HIAZIDE }\end{array}$ & 1959 & $6 \%$ & $\begin{array}{l}\text { C9B ACE INHIBITORS } \\
\text { COMBINAT }\end{array}$ \\
\hline HEPARIN & 1910 & $3 \%$ & $\begin{array}{l}\text { C5B VARICOSE } \\
\text { THERAPY,TOPICAL }\end{array}$ & METOPROLOL & 1975 & $3 \%$ & $\begin{array}{l}\text { C7A B-BLOCKING } \\
\text { AGENTS,PLAIN }\end{array}$ \\
\hline ATORVASTATIN & 1997 & $2 \%$ & \begin{tabular}{|l|} 
C10A \\
CHOLEST\&TRIGLY.R \\
EGULATOR
\end{tabular} & AMLODIPINE & 1990 & $3 \%$ & $\begin{array}{l}\text { C8A CALCIUM } \\
\text { ANTAGONIST PLAIN }\end{array}$ \\
\hline METOPROLOL & 1975 & $2 \%$ & $\begin{array}{l}\text { C7A B-BLOCKING } \\
\text { AGENTS,PLAIN }\end{array}$ & $\begin{array}{l}\text { CRATAEGUS } \\
\text { OXYACANTHA }\end{array}$ & & $3 \%$ & $\begin{array}{l}\text { C1X ALL OTHER } \\
\text { CARDIAC PREPS }\end{array}$ \\
\hline $\begin{array}{l}\text { HYDROCHLOROT } \\
\text { HIAZIDE }\end{array}$ & 1959 & $2 \%$ & $\begin{array}{l}\text { C9B ACE } \\
\text { INHIBITORS } \\
\text { COMBINAT }\end{array}$ & FUROSEMIDE & 1964 & $3 \%$ & C3A DIURETICS \\
\hline TORASEMIDE & 1992 & $2 \%$ & C3A DIURETICS & BISOPROLOL & 1986 & $3 \%$ & $\begin{array}{l}\text { C7A B-BLOCKING } \\
\text { AGENTS,PLAIN }\end{array}$ \\
\hline AMLODIPINE & 1990 & $2 \%$ & $\begin{array}{l}\text { C8A CALCIUM } \\
\text { ANTAGONIST PLAIN }\end{array}$ & GINKGO BILOBA & 1965 & $3 \%$ & $\begin{array}{l}\text { C4A CEREBR/PERIPH } \\
\text { VASOTHERAP }\end{array}$ \\
\hline ATENOLOL & 1976 & $2 \%$ & $\begin{array}{l}\text { C7A B-BLOCKING } \\
\text { AGENTS,PLAIN }\end{array}$ & SIMVASTATIN & 1988 & $3 \%$ & $\begin{array}{l}\text { C10A } \\
\text { CHOLEST\&TRIGLY.RE } \\
\text { GULATOR }\end{array}$ \\
\hline SIMVASTATIN & 1988 & $2 \%$ & $\begin{array}{l}\text { C1OA } \\
\text { CHOLEST\&TRIGLY.R } \\
\text { EGULATOR }\end{array}$ & HEPARIN & 1910 & $3 \%$ & $\begin{array}{l}\text { C5B VARICOSE } \\
\text { THERAPY,TOPICAL }\end{array}$ \\
\hline
\end{tabular}


Table 3

Descriptive statistics

\begin{tabular}{|c|c|c|c|c|}
\hline Variable & MEAN & STD. DEV. & MIN & MAX \\
\hline $\begin{array}{l}\text { number of hospital discharges in which the principal } \\
\text { diagnosis was cardiovascular disease per } 100,000 \\
\text { population }\end{array}$ & 2330 & 963 & 478 & 4710 \\
\hline $\begin{array}{l}\text { number of hospital days in which the principal diagnosis } \\
\text { was cardiovascular disease per 100,000 population }\end{array}$ & 23701 & 14935 & 4646 & 67314 \\
\hline $\begin{array}{l}\text { average length of stay in hospital discharges in which the } \\
\text { principal diagnosis was cardiovascular disease }\end{array}$ & 9.708 & 2.949 & 4.7 & 17.3 \\
\hline $\begin{array}{l}\text { age-standardized number of deaths caused by diseases of } \\
\text { the circulatory system per } 100,000 \text { population }\end{array}$ & 280 & 115 & 123 & 562 \\
\hline $\begin{array}{l}\text { potential years of life lost due to diseases of the circulatory } \\
\text { system before age } 70 \text { per } 100,000 \text { population }\end{array}$ & 743.84 & 361.8 & 333 & 1988 \\
\hline $\begin{array}{l}\text { the number of standard units of cardiovascular drugs per } \\
\text { person }\end{array}$ & 0.143 & 0.062 & 0.005 & 0.279 \\
\hline $\begin{array}{l}\text { fraction of standard units whose active ingredients were } \\
\text { launched after } 1995\end{array}$ & $4.2 \%$ & $4.7 \%$ & $0.0 \%$ & $21.8 \%$ \\
\hline $\begin{array}{l}\text { fraction of standard units whose active ingredients were } \\
\text { launched after } 1990\end{array}$ & $7.4 \%$ & $6.2 \%$ & $0.0 \%$ & $24.9 \%$ \\
\hline $\begin{array}{l}\text { number of computed tomography scanners per million } \\
\text { population }\end{array}$ & 16.281 & 12.588 & 3.5 & 92.6 \\
\hline $\begin{array}{l}\text { number of magnetic resonance imaging units per million } \\
\text { population }\end{array}$ & 6.752 & 6.058 & 0.6 & 40.1 \\
\hline population (in thousands) & 37,658 & 55,552 & 267 & 296,972 \\
\hline fraction of the population age 65 and over & $13.9 \%$ & $3.2 \%$ & $5.0 \%$ & $20.0 \%$ \\
\hline per capita GDP (in PPP US dollars) & $\$ 22,866$ & $\$ 8,360$ & $\$ 5,558$ & $\$ 48,162$ \\
\hline average number of calories consumed per person per day & 3334 & 253 & 2768 & 3817 \\
\hline per capita expenditure on tobacco (in PPP US dollars) & $\$ 327$ & $\$ 346$ & $\$ 26$ & $\$ 2,662$ \\
\hline per capita expenditure on alcohol (in PPP US dollars) & $\$ 279$ & $\$ 138$ & $\$ 43$ & $\$ 788$ \\
\hline $\begin{array}{l}\text { fraction of the population with education at or below the } \\
\text { lower secondary level (ISCED 0/1/2) }\end{array}$ & $29.8 \%$ & $17.2 \%$ & $10.7 \%$ & $79.0 \%$ \\
\hline $\begin{array}{l}\text { fraction of the population with education at the upper } \\
\text { secondary or post-secondary, non-tertiary level (ISCED 3/4) }\end{array}$ & $47.4 \%$ & $16.3 \%$ & $11.9 \%$ & $76.7 \%$ \\
\hline $\begin{array}{l}\text { fraction of the population with education at the tertiary level } \\
\text { (ISCED 5A/6) }\end{array}$ & $14.8 \%$ & $5.4 \%$ & $6.0 \%$ & $29.8 \%$ \\
\hline
\end{tabular}


Table 4

Estimates of eq. (1): In $Y_{i t}=\beta$ rx_post1995\% $\%_{i t}+\gamma Z_{i t}+\alpha_{i}+\delta_{t}+\varepsilon_{i t}$

\begin{tabular}{|c|c|c|c|c|c|c|c|c|c|c|c|c|c|c|c|}
\hline Model & \multicolumn{3}{|c|}{1} & \multicolumn{3}{|c|}{2} & \multicolumn{3}{|c|}{3} & \multicolumn{3}{|c|}{4} & \multicolumn{3}{|c|}{5} \\
\hline Dep. Var. & \multicolumn{3}{|c|}{ In(n_discharges) } & \multicolumn{3}{|c|}{$\ln$ (alos) } & \multicolumn{3}{|c|}{ In(n_days) } & \multicolumn{3}{|c|}{ In(n_deaths) } & \multicolumn{3}{|c|}{$\ln (p y l l)$} \\
\hline Parameter & estimate & t-value & prob>t & estimate & t-value & prob>t & estimate & t-value & prob>t & estimate & t-value & prob $>t$ & estimate & t-value & prob>t \\
\hline rx_post1995\% & -4.013 & -5.51 & $<.0001$ & -0.858 & -2.30 & 0.0271 & -4.870 & -5.83 & $<.0001$ & -0.846 & -2.88 & 0.0059 & 0.333 & 0.61 & 0.5447 \\
\hline $\ln \left(n \_c v \_s u\right)$ & 0.006 & 0.47 & 0.6418 & 0.012 & 1.78 & 0.0831 & 0.018 & 1.20 & 0.2363 & 0.014 & 2.12 & 0.0391 & 0.021 & 1.74 & 0.0886 \\
\hline In(ct_scan) & 0.289 & 2.63 & 0.0123 & 0.058 & 1.03 & 0.3084 & 0.347 & 2.75 & 0.009 & -0.029 & -0.69 & 0.4911 & -0.041 & -0.53 & 0.5994 \\
\hline $\ln (\mathrm{mri})$ & -0.043 & -0.76 & 0.4545 & 0.046 & 1.58 & 0.1224 & 0.003 & 0.05 & 0.9629 & 0.007 & 0.22 & 0.8235 & -0.068 & -1.24 & 0.2192 \\
\hline $\ln$ (calories) & -1.324 & -2.48 & 0.0178 & 0.754 & 2.75 & 0.009 & -0.571 & -0.93 & 0.3583 & 0.464 & 1.81 & 0.0764 & 1.239 & 2.60 & 0.0122 \\
\hline $\ln$ (tobacco) & 0.463 & 2.94 & 0.0055 & -0.168 & -2.09 & 0.0434 & 0.295 & 1.63 & 0.1111 & 0.052 & 0.70 & 0.4888 & -0.133 & -0.97 & 0.3378 \\
\hline In(alcohol) & -0.233 & -1.03 & 0.3094 & 0.539 & 4.65 & $<.0001$ & 0.306 & 1.18 & 0.2448 & -0.061 & -0.60 & 0.5516 & -0.195 & -1.04 & 0.3027 \\
\hline In(population) & 1.936 & 1.37 & 0.1781 & 0.476 & 0.66 & 0.5141 & 2.412 & 1.49 & 0.1444 & -0.030 & -0.05 & 0.9632 & 0.326 & 0.27 & 0.7877 \\
\hline age_ge_65\% & 0.080 & 2.58 & 0.0139 & -0.007 & -0.41 & 0.6845 & 0.073 & 2.06 & 0.0458 & & & & & & \\
\hline $\ln (g d p)$ & 0.160 & 0.42 & 0.6792 & -0.518 & -2.63 & 0.0123 & -0.357 & -0.81 & 0.4232 & -0.072 & -0.40 & 0.6898 & 0.267 & 0.80 & 0.4259 \\
\hline edu_low $\%$ & -0.023 & -1.93 & 0.0603 & 0.004 & 0.63 & 0.5323 & -0.019 & -1.40 & 0.168 & 0.015 & 2.69 & 0.0098 & 0.036 & 3.59 & 0.0008 \\
\hline edu_mid\% & -0.016 & -1.01 & 0.321 & 0.011 & 1.35 & 0.1857 & -0.005 & -0.27 & 0.7851 & 0.015 & 2.14 & 0.0371 & 0.035 & 2.70 & 0.0096 \\
\hline edu_max\% & 0.020 & 0.82 & 0.4176 & 0.039 & 3.12 & 0.0034 & 0.058 & 2.11 & 0.0416 & 0.022 & 2.54 & 0.0142 & 0.034 & 2.14 & 0.0371 \\
\hline year 1995 & 0.182 & 1.27 & 0.211 & 0.290 & 3.94 & 0.0003 & 0.472 & 2.87 & 0.0066 & 0.207 & 3.56 & 0.0008 & 0.301 & 2.79 & 0.0074 \\
\hline year 1996 & 0.100 & 0.74 & 0.4663 & 0.209 & 3.02 & 0.0045 & 0.309 & 1.99 & 0.0539 & 0.162 & 3.18 & 0.0025 & 0.268 & 2.83 & 0.0067 \\
\hline year 1997 & 0.082 & 0.73 & 0.4688 & 0.167 & 2.93 & 0.0056 & 0.249 & 1.95 & 0.0587 & 0.129 & 2.79 & 0.0074 & 0.245 & 2.86 & 0.0062 \\
\hline year 1998 & 0.101 & 1.09 & 0.2843 & 0.126 & 2.65 & 0.0115 & 0.227 & 2.13 & 0.0395 & 0.117 & 2.94 & 0.0049 & 0.217 & 2.94 & 0.005 \\
\hline year 1999 & 0.102 & 1.39 & 0.1737 & 0.106 & 2.82 & 0.0076 & 0.208 & 2.47 & 0.0182 & 0.098 & 3.01 & 0.0041 & 0.185 & 3.08 & 0.0034 \\
\hline year 2000 & 0.095 & 1.64 & 0.1091 & 0.088 & 2.98 & 0.005 & 0.183 & 2.76 & 0.0088 & 0.057 & 2.20 & 0.0323 & 0.136 & 2.86 & 0.0063 \\
\hline year 2001 & 0.065 & 1.71 & 0.0959 & 0.068 & 3.46 & 0.0013 & 0.133 & 3.03 & 0.0043 & 0.028 & 1.52 & 0.1352 & 0.090 & 2.62 & 0.0116 \\
\hline year 2002 & 0.037 & 1.40 & 0.1702 & 0.050 & 3.71 & 0.0006 & 0.087 & 2.88 & 0.0065 & 0.019 & 1.46 & 0.1509 & 0.058 & 2.34 & 0.0231 \\
\hline year 2003 & 0.000 & . &. & 0.000 &. &. & 0.000 & & . & 0.000 &. &. & 0.000 & . &. \\
\hline & & & & & & & & & & & & & & & \\
\hline $\mathrm{R}^{2}$ & 0.993 & & & 0.997 & & & 0.996 & & & 0.997 & & & 0.990 & & \\
\hline $\begin{array}{l}\text { Degrees of } \\
\text { freedom }\end{array}$ & & & & & & & & & & & & & & & \\
\hline Model & 36 & & & 36 & & & 36 & & & 33 & & & 33 & & \\
\hline Error & 39 & & & 39 & & & 39 & & & 49 & & & 49 & & \\
\hline Corrected Total & 75 & & & 75 & & & 75 & & & 82 & & & 82 & & \\
\hline
\end{tabular}

Note: all models include country fixed effects. 
Table 5

Estimates of eq. (1): In $Y_{i t}=\beta$ rx_post1990\% $\%_{i t}+\gamma Z_{i t}+\alpha_{i}+\delta_{t}+\varepsilon_{i t}$

\begin{tabular}{|c|c|c|c|c|c|c|c|c|c|c|c|c|c|c|c|}
\hline \begin{tabular}{|l|} 
Model \\
\end{tabular} & \multicolumn{3}{|c|}{1} & \multicolumn{3}{|c|}{2} & \multicolumn{3}{|c|}{3} & \multicolumn{3}{|c|}{4} & \multicolumn{3}{|c|}{5} \\
\hline Dep. Var. & \multicolumn{3}{|c|}{ In(n_discharges) } & \multicolumn{3}{|c|}{$\ln ($ alos $)$} & \multicolumn{3}{|c|}{ In(n_days) } & \multicolumn{3}{|c|}{$\ln \left(\mathrm{n} \_\right.$deaths $)$} & \multicolumn{3}{|c|}{$\ln (p y \| l)$} \\
\hline Parameter & estimate & t-value & prob>t & estimate & t-value & prob $>t$ & estimate & $\mathrm{t}$-value & prob>t & estimate & t-value & prob>t & estimate & t-value & prob $>t$ \\
\hline rx_post1990\% & -3.270 & -3.01 & 0.0046 & -1.087 & -2.35 & 0.0239 & -4.357 & -3.52 & 0.0011 & -0.915 & -2.67 & 0.0103 & -0.296 & -0.47 & 0.6406 \\
\hline$\overline{l n\left(n \_c v \_s u\right)}$ & 0.011 & 0.74 & 0.465 & 0.013 & 1.98 & 0.055 & 0.024 & 1.39 & 0.1729 & 0.015 & 2.32 & 0.0245 & 0.019 & 1.6 & 0.1169 \\
\hline $\ln (\mathrm{ct}$ scan) & 0.205 & 1.58 & 0.1232 & 0.051 & 0.92 & 0.3629 & 0.256 & 1.73 & 0.0917 & $\begin{array}{l}-0.028 \\
\end{array}$ & -0.67 & 0.5087 & -0.058 & -0.74 & 0.4627 \\
\hline $\mid \ln (\mathrm{mri})$ & -0.023 & -0.34 & 0.7383 & 0.052 & 1.78 & 0.0828 & 0.029 & 0.37 & 0.7134 & 0.023 & 0.77 & 0.4426 & -0.066 & -1.18 & 0.2439 \\
\hline$\overline{\ln \text { (calories) }}$ & -1.729 & -2.68 & 0.0106 & 0.644 & 2.35 & 0.0239 & -1.085 & -1.48 & 0.1469 & 0.374 & 1.43 & 0.1584 & 1.218 & 2.54 & 0.0144 \\
\hline $\ln$ (tobacco) & 0.536 & 2.77 & 0.0084 & -0.139 & -1.69 & 0.0989 & 0.397 & 1.81 & 0.0785 & 0.082 & 1.11 & 0.2727 & -0.156 & -1.15 & 0.2541 \\
\hline $\ln ($ alcohol $)$ & -0.415 & -1.54 & 0.1318 & 0.497 & 4.33 & 0.0001 & 0.082 & 0.27 & 0.7915 & -0.093 & -0.91 & 0.3663 & -0.187 & -1 & 0.3232 \\
\hline $\ln$ (population) & 1.085 & 0.64 & 0.5289 & 0.521 & 0.72 & 0.4774 & 1.606 & 0.83 & 0.4134 & -0.187 & -0.29 & 0.7697 & 1.045 & 0.89 & 0.376 \\
\hline age_ge_65\% & 0.097 & 2.59 & 0.0133 & -0.002 & -0.11 & 0.9099 & 0.095 & 2.24 & 0.0311 & & & & & & \\
\hline $\ln (\mathrm{gdp})$ & 0.594 & 1.3 & 0.2018 & -0.413 & -2.12 & 0.0405 & 0.182 & 0.35 & 0.7291 & $\begin{array}{l}-0.021 \\
\end{array}$ & -0.12 & 0.9081 & 0.290 & 0.86 & 0.3922 \\
\hline edu_low\% & -0.031 & -2.16 & 0.0369 & 0.002 & 0.31 & 0.7583 & -0.029 & -1.78 & 0.0823 & 0.012 & 2.14 & 0.0378 & 0.037 & 3.71 & 0.0005 \\
\hline edu_mid\% & -0.020 & -1.06 & 0.2971 & 0.010 & 1.2 & 0.2363 & -0.010 & -0.48 & 0.6345 & 0.012 & 1.71 & 0.0933 & 0.033 & 2.51 & 0.0153 \\
\hline edu_max\% & 0.007 & 0.24 & 0.8082 & 0.039 & 3.16 & 0.0031 & 0.046 & 1.4 & 0.1707 & 0.023 & 2.68 & 0.0099 & 0.036 & 2.23 & 0.0306 \\
\hline year 1995 & 0.208 & 1.2 & 0.2375 & 0.284 & 3.85 & 0.0004 & 0.491 & 2.49 & 0.017 & 0.214 & 3.67 & 0.0006 & 0.262 & 2.44 & 0.0182 \\
\hline year 1996 & 0.125 & 0.77 & 0.4487 & 0.202 & 2.89 & 0.0062 & 0.327 & 1.75 & 0.0873 & 0.168 & 3.28 & 0.0019 & 0.227 & 2.42 & 0.0195 \\
\hline year 1997 & 0.128 & 0.95 & 0.347 & 0.163 & 2.85 & 0.0069 & 0.292 & 1.9 & 0.0645 & 0.134 & 2.88 & 0.0059 & 0.204 & 2.38 & 0.0214 \\
\hline year 1998 & 0.149 & 1.34 & 0.1893 & 0.125 & 2.63 & 0.012 & 0.275 & 2.16 & 0.0371 & 0.123 & 3.12 & 0.003 & 0.180 & 2.47 & 0.017 \\
\hline year 1999 & 0.133 & 1.5 & 0.141 & 0.105 & 2.8 & 0.008 & 0.238 & 2.37 & 0.023 & 0.101 & 3.08 & 0.0033 & 0.158 & 2.62 & 0.0116 \\
\hline year 2000 & 0.110 & 1.59 & 0.1196 & 0.090 & 3.04 & 0.0042 & 0.200 & 2.54 & 0.0153 & 0.060 & 2.35 & 0.0229 & 0.119 & 2.51 & 0.0153 \\
\hline year 2001 & 0.070 & 1.52 & 0.1361 & 0.069 & 3.52 & 0.0011 & 0.138 & 2.65 & 0.0115 & 0.030 & 1.58 & 0.1195 & 0.080 & 2.31 & 0.025 \\
\hline year 2002 & 0.045 & 1.43 & 0.1618 & 0.052 & 3.86 & 0.0004 & 0.097 & 2.7 & 0.0103 & 0.021 & 1.56 & 0.1243 & 0.055 & 2.21 & 0.0314 \\
\hline year 2003 & 0.000 & & & 0.000 & & & 0.000 & . & & 0.000 & & & 0.000 & & \\
\hline $\mathrm{R}^{2}$ & 0.990 & & & 0.997 & & & 0.994 & & & 0.997 & & & 0.990 & & \\
\hline $\begin{array}{l}\text { Degrees of } \\
\text { freedom }\end{array}$ & & & & & & & & & & & & & & & \\
\hline Model & 36 & & & 36 & & & 36 & & & 33 & & & 33 & & \\
\hline Error & 39 & & & 39 & & & 39 & & & 49 & & & 49 & & \\
\hline \begin{tabular}{|c|} 
Corrected Total \\
\end{tabular} & 75 & & & 75 & & & 75 & & & 82 & & & 82 & & \\
\hline
\end{tabular}

Note: all models include country fixed effects. 
Table 6

$\%$ increase in dependent variable in 2004 if no 1995-2004 change in drug vintage

\begin{tabular}{|c|c|c|c|c|c|}
\hline & & \multirow{2}{*}{\multicolumn{4}{|c|}{ 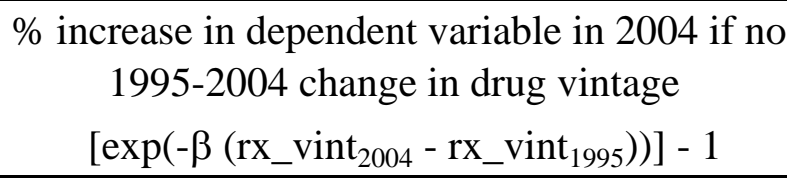 }} \\
\hline & & & & & \\
\hline $\begin{array}{l}\text { vintage measure } \\
\text { (rx_vint) }\end{array}$ & $\begin{array}{l}\text { 1995-2004 change in } \\
\text { vintage measure } \\
\left.\text { (rx_vint } 2004-\text { rx_vint }_{1995}\right)\end{array}$ & n_discharges & alos & n_days & n_deaths \\
\hline rx_post1995\% & $10 \%$ & $47 \%$ & $9 \%$ & $60 \%$ & $9 \%$ \\
\hline rx_post1990\% & $13 \%$ & $55 \%$ & $16 \%$ & $79 \%$ & $13 \%$ \\
\hline average & & $51 \%$ & $12 \%$ & $70 \%$ & $11 \%$ \\
\hline
\end{tabular}




\section{Table 7}

Estimates of the effect of cardiovascular drug vintage on per capita expenditure on cardiovascular drugs

\begin{tabular}{|l|c|c|c|c|}
\hline $\begin{array}{l}\text { vintage measure } \\
\text { (rx_vint) }\end{array}$ & $\pi$ & t-stat & p-value & {$\left[\exp \left(-\pi\left(\right.\right.\right.$ rx_vint $_{2004}-$ rx_vint $\left.\left.\left._{1995}\right)\right)\right]-1$} \\
\hline rx_post1995\% & 2.70 & 2.99 & 0.004 & $-22.90 \%$ \\
\hline rx_post1990\% & 2.16 & 2.34 & 0.022 & $-25.10 \%$ \\
\hline
\end{tabular}

Estimates of $\pi$ based on the two different drug vintage measures

$\ln \left(\right.$ cardio_rx_expend $\left._{\mathrm{it}}\right)=\pi \mathrm{rx} \_$vint $_{\mathrm{it}}+\gamma \ln \left(\mathrm{n} \_\mathrm{cv} \_\mathrm{su}_{\mathrm{it}}\right)+\alpha_{\mathrm{i}}+\delta_{\mathrm{t}}+\varepsilon_{\mathrm{it}}$ 